\title{
REVIEW
}

\section{Contribution of Impaired Mobility and General Symptoms to the Burden of Multiple Sclerosis}

Howard L. Zwibel

Received: November 9, 2009 / Published online: January 13, 2010 / Printed: January 29, 2010

(C) Springer Healthcare 2009

\begin{abstract}
Introduction: Few studies have evaluated the contribution of individual symptoms and impairments to the burden of multiple sclerosis (MS). This article reviews the contribution of walking impairment, fatigue, spasticity, depression, and pain, to quality of life (QOL) of the patient and economic burden of MS. Methods: Studies for inclusion were chosen from the literature that reported on QOL and costs in patients with MS, identified through PubMed searches (main search terms: "multiple sclerosis" combined with "quality of life," "costs," or "burden"). Articles were selected based on whether the analyses included evaluation of symptoms and impairments as contributory factors to QOL or costs. Results: Impaired mobility was ranked to be of high concern, and was suggested to be an important contributory factor to QOL, having a greater impact on physical components than mental components. Fatigue was associated with
\end{abstract}

Howard L. Zwibel $(\bowtie)$

The Multiple Sclerosis Center at Doctors Hospital,

6862 Granada Boulevard,

Coral Gables, Florida 33146, USA.

Email: zwibelmdms@aol.com
QOL, with effects on both physical and mental components of QOL, independent of disability level. Depression was inversely associated with QOL. Spasticity may affect physical components of QOL, and daily activities may be impacted in as many as $44 \%$ of patients with MS. Pain, occurring in up to $86 \%$ of patients with MS, impacts daily function and QOL across the range of physical and mental domains. The contribution of these impairments and symptoms to the economic burden has been less well characterized, although the importance of mobility to employment and productivity has been suggested by several studies. Conclusions: Evidence suggests that impaired mobility and symptoms such as fatigue, pain, depression, and spasticity are important contributory factors to the observed reduction in QOL, and in some cases, increased costs, associated with MS. There is a need for greater recognition of the presence and effects of these disabilities, and effective targeted treatment options for specific impairments, potentially resulting in improved QOL and reduced indirect costs.

Keywords: burden; costs; depression; fatigue; impairment; mobility; multiple sclerosis; pain; quality of life; spasticity; walking 


\section{INTRODUCTION}

Multiple sclerosis (MS) is a chronic disease characterized by increasing disability resulting from central nervous system inflammation, progressive demyelination, and axonal loss. MS has a prevalence of approximately 135 per 100,000 population in the US, which translates to approximately 400,000 individuals; and the global estimate is about 2.5 million. ${ }^{1}$ Diseasemodifying drugs (DMD) are the primary treatment strategy in MS. These drugs are used to reduce relapse rate and slow disease progression, but they do not repair pre-existing neuronal damage. However, data from the US suggest that $40 \%$ to $50 \%$ of individuals are not being treated with DMDs. ${ }^{2,3}$

Despite the need for managing the underlying disease, it is being increasingly recognized that it is the multiple symptoms and impairments often present in patients with MS including walking impairment, weakness, fatigue, cognitive impairment, bladder and bowel dysfunction, depression, visual impairment, and pain, that contribute to the burden of disease. ${ }^{1,4}$ This burden is manifested by reductions in patient functioning, ability to perform activities of daily living, and quality of life (QOL), as well as increased healthcare resource utilization and costs. ${ }^{4}$ Addressing these problems is important considering that many patients are not taking DMDs, and that even among those who do, the benefits of these drugs on symptoms and impairments have not been clearly established. Consequently, the treatment paradigm has shifted to include the implementation of a more comprehensive approach that encompasses the disease and the patient by targeting the specific issues affecting patient function and QOL. ${ }^{5-8}$ This is especially important when considering that patients with MS and their treating physicians may not necessarily agree on which dimensions of health are most important. Some physicians generally consider the physical manifestations of the disease, whereas patients often place a high emphasis on vitality, general health, and mental health. ${ }^{9}$ Lower health status and QOL have been reported in individuals with MS relative to general population norms, age- and gendermatched controls, and individuals with other prevalent chronic conditions. ${ }^{10-17}$ Reduced QOL is consistent regardless of the instrument used including the Medical Outcomes Survey 36-item Short Form (SF-36) ${ }^{10-12}$ and 12-item Short Form (SF-12), ${ }^{13}$ the EuroQol 5D (EQ-5D), ${ }^{14-16}$ and the Health Utilities Index Mark 3 (HUI3). ${ }^{17}$

Progression of disease and associated disabilities resulting from dysfunction of the pyramidal, cerebellar, visual, and other functional systems has traditionally been assessed using the disease-specific Expanded Disability Status Scale (EDSS). ${ }^{18}$ The EDSS ranges from 0, representing a normal neurologic exam, to 10, representing death due to MS. Staging of disability by the EDSS is weighted toward walking impairment in the middle range of the scale (4.5 to 7.5), and an individual with a score $\leq 3.5$ is considered to be fully ambulatory. However, objective walking, gait, and balance impairment have been observed in patients with EDSS scores $<3,{ }^{19,20}$ and even at what are considered low overall disability levels (between 1 and 3.5) substantial proportions of patients report walking difficulties (22\%), cognitive dysfunction (38\%), and fatigue $(60 \%){ }^{21}$

Due to its early onset, often within the third or fourth decade of life and progressing through the most productive years, ${ }^{22} \mathrm{MS}$ is associated with a high socioeconomic burden. The total average annual costs in the US have been conservatively estimated at $\$ 47,215,{ }^{15}$ with indirect costs consistently shown to be the predominant driver of the economic burden. ${ }^{15,23-26}$ Proportionately, lost productivity represents the single highest 
component cost (44\%), and while the cost of individual DMDs used to treat MS is high, the component cost of these drugs represents only $22 \%$ of MS costs (Figure 1 ). ${ }^{15}$

Few studies have specifically focused on the contribution of individual impairments to the patient burden (ie, QOL). Additionally, their contribution to the economic burden has been explored to a lesser extent than their effects on QOL, since incremental costs related to symptoms are difficult to quantify. However, some data are available from broader studies of the impact of MS on socioeconomic burden, and these data may help characterize the contribution of symptoms to the burden of MS. Therefore, the purpose of this article is to review the contribution of symptoms and impairments frequently occurring in patients with MS to QOL and costs.

\section{METHODS}

Although this was not a systematic review, studies for inclusion were chosen from the literature that reported on QOL and costs in patients with MS, identified from PubMed searches for articles published up until January 31, 2009. The main search terms were "multiple sclerosis" combined with "quality of life," "costs," or "burden" with the limitation of English language publications. Selection of articles was based on whether the analyses included evaluation of specific symptoms and impairments as contributory factors to QOL or costs. Reference lists of the identified articles were additionally hand-searched for potential studies that may have been missed using the original search criteria.

The selected articles relied on a variety of instruments to measure health status and QOL outcomes. Although most of the instruments are generic rather than disease specific, they are widely used and accepted for assessing QOL across a range of disease states and conditions. These instruments included the SF-36 and the shorter SF-12. The former is the most widely used generic instrument for evaluating health status and QOL, and consists of eight domains (physical functioning, role-physical, bodily pain, general health, vitality, social functioning, role-emotional, and mental health) as well as physical and mental component summary scores, ${ }^{27}$ while the latter is a 12 -item version of

Figure 1. Distribution of components contributing to the economic burden of multiple sclerosis in the US, adjusted for an estimated national average use of $52 \%$ for disease-modifying drugs. Reprinted with permission from Kobelt G et al. Costs and quality of life in multiple sclerosis: a cross-sectional study in the United States. Neurology. 2006;66:1696-1702. ${ }^{15}$

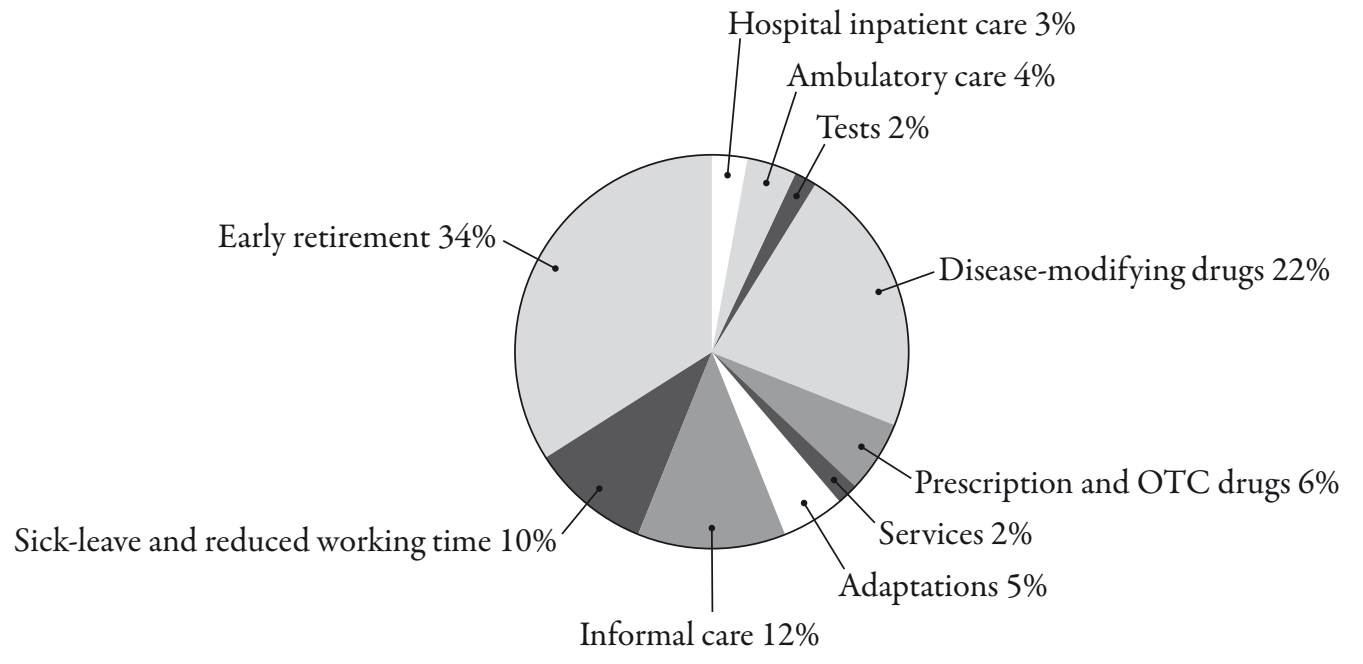


the SF-36 that measures the same domains. ${ }^{28}$ The SF-36 was also the basis for the disease-specific 54-item Multiple Sclerosis Quality of Life instrument (MSQOL-54), which incorporates items of relevance to patients with MS such as bowel and bladder function, sexual function, cognitive function, and health distress. ${ }^{29}$ Other instruments used in the studies reviewed here were the HUI3, a generic multiattribute health status classification system that characterizes health states based on functional capacity defined by eight attributes (vision, hearing, speech, ambulation, dexterity, emotion, cognition, and pain and discomfort), ${ }^{30}$ and the EQ-5D. The EQ-5D is a patient preference-based instrument consisting of five items that assess the level of difficulty (none, some/moderate, extreme) respondents report for the health status domains of mobility, self-care, usual activities, pain/discomfort, and anxiety/ depression. ${ }^{31}$ Also used, although less frequently, is the World Health Organization Quality of LifeBrief Version (WHOQOL-BREF), an instrument that consists of 26 items that measure the broad domains of physical health, psychological health, social relationships, and environment. ${ }^{32}$

When considering the data reviewed here, it should be borne in mind that it is difficult to evaluate individual symptoms and impairments since there are often interactions between them, such that a specific symptom or impairment may overlap with others such as fatigue and depression, and mobility and spasticity.

\section{IMPACT OF SYMPTOMS AND IMPAIRMENTS ON HEALTH- RELATED QOL}

Mobility impairment is one of the most well-recognized characteristics of MS, and has been reported in up to $90 \%$ of individuals. ${ }^{10,33,34}$ Among individuals treated with DMDs, only $52 \%$ reported some improvement in mobility. ${ }^{10}$
According to the World Health Organization International Classification of Functioning, Disability and Health (ICF), mobility and walking are distinctly defined: mobility is moving by changing body position or location or by transferring from one place to another, by carrying, moving or manipulating objects, by walking, running or climbing, and by using various forms of transportation; walking is moving along a surface on foot, step by step, so that one foot is always on the ground, such as when strolling, sauntering, walking forwards, backwards, or sideways. ${ }^{35}$ The progressive worsening of walking results in the need for assistive devices, and estimates from a longitudinal study suggest that by 15 years after diagnosis, there is an approximate $40 \%$ probability for needing some form of walking assistance and a $25 \%$ probability for use of a wheelchair. ${ }^{36}$

Impaired mobility, especially related to walking ability, impacts functional activity and independence. Gait parameters including walking speed and stride length have been reported to be significant predictors of patient dependence in activities of daily living $(P<0.05) .{ }^{37}$ It is therefore not surprising that mobility impairment was ranked high among patient concerns. ${ }^{38,39}$ In a survey conducted in the US, mobility was given the highest priority by $65 \%$ of patients among factors affecting QOL. ${ }^{38}$ Similarly, in patients with MS duration $<5$ years and $>15$ years, walking was ranked first among 13 bodily functions by the greatest proportion of patients regardless of level of disability and disease duration; approximately $37 \%$ and $28 \%$ of those with duration $<5$ years and $>15$ years, respectively. ${ }^{39}$

Using the EQ-5D, Hemmett et al. ${ }^{10}$ reported that of the five dimensions (mobility, self-care, usual activities, pain/discomfort, depression/ anxiety), walking was the dimension with the highest proportion of patients reporting difficulties (89.5\%), paralleled by usual activities 
(89.2\%) - a dimension that may be considered to be mobility-related since it encompasses work, housework, and family and leisure activities. ${ }^{10}$ However, Gottberg et al. ${ }^{14}$ reported that the proportion of patients reporting mobility problems (67\%), was second to the proportion reporting pain $(69 \%)$, a difference from the former study that may be ascribed in part to the greater proportion of patients with progressive disease $(58 \%$ vs. 35\%) and by a longer mean disease duration (19 years vs. 13 years).

Similar to the EQ-5D, the HUI3 is a health utility index that characterizes health states defined by eight attributes (vision, hearing, speech, ambulation, dexterity, emotion, cognition, and pain and discomfort). Analysis of scores from the HUI3, collected from individuals with and without MS as part of a Canadian cross-sectional population health survey, showed that the largest difference in individual attribute scores between individuals with and without MS was for ambulation $(0.26$; $95 \% \mathrm{CI}=0.20-0.32)$ (Figure 2). ${ }^{17}$ In a study based on data from the Sonya Slifka Longitudinal MS Study, scores on the physical component summary of the SF-12 were significantly worse among MS patients with difficulty walking relative to those without such difficulty ( 31.3 vs. $45.9 ; P<0.05) .{ }^{13}$ It should be noted that this study, with patients representing a broad range of disability levels across all regions of the US, provides a comprehensive list of symptoms and impairments and shows that patients with these impairments have significantly worse scores on the physical and mental component summary of the SF-12 relative to patients without these impairments (Table 1$) \cdot{ }^{13}$ Some of these health problems, including symptoms such as fatigue, pain, and depression, affect QOL independent of the overall disease impact. ${ }^{40}$

Fatigue is a major complaint among individuals with MS. Up to $95 \%$ of patients report fatigue, ${ }^{10,41,42}$ which is frequently severe ${ }^{43}$ and is cited among the worst symptoms by a majority of patients (69\%) regardless of neurologic impairment. ${ }^{41}$ Fatigue is subjective and multidimensional, and is therefore difficult to evaluate, especially in chronic, complex diseases such as MS. ${ }^{44}$ The vitality domain of the SF-36 can be considered a proxy for fatigue, and the scores on this domain are significantly lower among individuals with MS relative to general population norms. ${ }^{11,12,40,45,46}$ Additional evidence from several studies also supports fatigue as an independent predictor of QOL, and in some cases with effects on specific QOL components. ${ }^{40,47-51}$ In particular, significant effects on both the physical and mental components of QOL were reported by Benedict et al. $(P<0.001),{ }^{50}$ and Merkelbach et al. ( $P$ values from $<0.05$ to $<0.001),{ }^{49}$ with the former using the MSQOL-54 and the latter using the SF-36.

Figure 2. Mean scores, adjusted for age, sex, education, marital status, social assistance, and number of medical conditions other than multiple sclerosis (MS), on the Health Utility Index Mark 3 (HUI3) attributes among patients with MS and the general population. Scores are presented in order of the greatest difference between $\mathrm{MS}$ and the general population. ${ }^{*} P<0.05$ for between-group differences after adjusting for covariates. Reprinted with permission from Jones et al. ${ }^{17}$

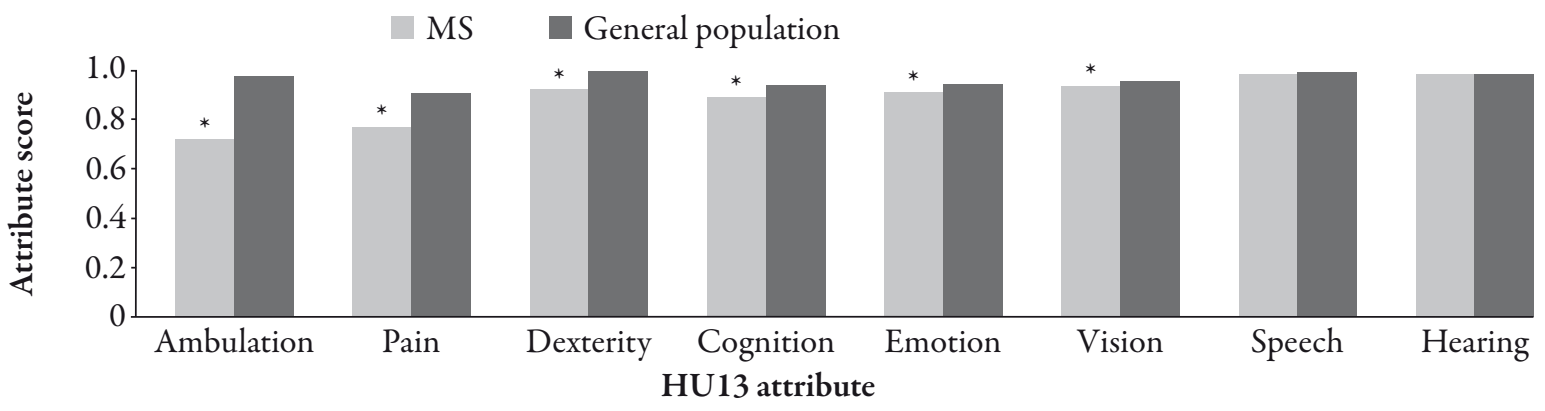


Table 1. Mean scores on physical component (PCS12) and mental component (MCS12) summary scales of the Medical Outcomes Survey 12-item Short Form (SF-12) among multiple sclerosis patients with and without specific symptomatic impairments. Reprinted with permission from Wu et al. ${ }^{13}$

\begin{tabular}{|c|c|c|c|c|c|}
\hline & \multirow[b]{2}{*}{$n(\%)^{a}$} & \multicolumn{2}{|c|}{ PCS12 score } & \multicolumn{2}{|c|}{ MCS12 score } \\
\hline & & $\operatorname{Mean}(\mathrm{SE})^{a}$ & Effect size ${ }^{b}$ & Mean $(\mathrm{SE})^{a}$ & Effect size $^{\mathrm{b}}$ \\
\hline Fatigue & & & -1.11 & & -0.77 \\
\hline Yes & $1745(83)$ & $34.25(0.27)$ & & $47.54(0.28)$ & \\
\hline No & $363(17)$ & $45.34(0.64)$ & & $55.23(0.48)$ & \\
\hline Difficulty walking & & & -1.46 & & -0.09 \\
\hline Yes & $1316(67)$ & $31.31(0.25)$ & & $48.55(0.33)$ & \\
\hline No & $792(33)$ & $45.92(0.41)$ & & $49.47(0.41)$ & \\
\hline Spasms/stiffness & & & -1.09 & & -0.27 \\
\hline Yes & $1274(63)$ & $32.10(0.29)$ & & $47.85(0.34)$ & \\
\hline No & $833(37)$ & $43.01(0.43)$ & & $50.56(0.39)$ & \\
\hline Bladder problems & & & -0.88 & & -0.24 \\
\hline Yes & $1168(60)$ & $32.58(0.30)$ & & $47.88(0.34)$ & \\
\hline No & $937(40)$ & $41.40(0.43)$ & & $50.27(0.38)$ & \\
\hline Cognitive/memory problems & & & -0.48 & & -0.71 \\
\hline Yes & $1175(56)$ & $34.00(0.33)$ & & $45.70(0.34)$ & \\
\hline No & $917(44)$ & $38.75(0.42)$ & & $52.82(0.34)$ & \\
\hline Pain/unpleasant sensations & & & -0.87 & & -0.40 \\
\hline Yes & $1166(54)$ & $32.12(0.33)$ & & $47.02(0.35)$ & \\
\hline No & $941(46)$ & $40.85(0.37)$ & & $51.05(0.36)$ & \\
\hline Emotional/mood problems & & & -0.39 & & -1.26 \\
\hline Yes & $801(38)$ & $33.72(0.39)$ & & $41.01(0.38)$ & \\
\hline No & $1304(62)$ & $37.57(0.35)$ & & $53.56(0.25)$ & \\
\hline Vision problems & & & -0.50 & & -0.38 \\
\hline Yes & $781(37)$ & $33.00(0.40)$ & & $46.48(0.44)$ & \\
\hline No & $1324(63)$ & $38.02(0.34)$ & & $50.28(0.31)$ & \\
\hline Dizziness & & & -0.54 & & -0.42 \\
\hline Yes & $750(36)$ & $32.64(0.41)$ & & $46.15(0.44)$ & \\
\hline No & $1356(64)$ & $38.08(0.34)$ & & $50.37(0.31)$ & \\
\hline Bowel problems & & & -0.84 & & -0.34 \\
\hline Yes & $677(34)$ & $30.65(0.36)$ & & $46.63(0.45)$ & \\
\hline No & $1425(66)$ & $39.04(0.33)$ & & $49.99(0.31)$ & \\
\hline Sexual problems & & & -0.64 & & -0.43 \\
\hline Yes & $594(31)$ & $31.76(0.42)$ & & $45.90(0.49)$ & \\
\hline No & 1466 (69) & $38.20(0.33)$ & & $50.15(0.30)$ & \\
\hline Tremors & & & -0.76 & & -0.28 \\
\hline Yes & $606(30)$ & $30.85(0.39)$ & & $46.94(0.50)$ & \\
\hline No & $1495(70)$ & $38.42(0.33)$ & & $49.71(0.30)$ & \\
\hline Difficulty moving arms & & & -0.89 & & -0.42 \\
\hline Yes & $460(24)$ & $29.34(0.41)$ & & $45.69(0.57)$ & \\
\hline No & $1647(76)$ & $38.25(0.31)$ & & $49.84(0.28)$ & \\
\hline Swallowing problems & & & -0.71 & & -0.40 \\
\hline Yes & $426(22)$ & $30.61(0.48)$ & & $45.74(0.56)$ & \\
\hline No & $1679(78)$ & $37.67(0.30)$ & & $49.72(0.28)$ & \\
\hline Speech problems & & & -0.56 & & -0.57 \\
\hline Yes & $417(20)$ & $31.65(0.51)$ & & $44.30(0.60)$ & \\
\hline No & $1685(80)$ & $37.28(0.30)$ & & $50.01(0.28)$ & \\
\hline Seizures & & & -0.40 & & -0.76 \\
\hline Yes & $45(2)$ & $32.23(1.61)$ & & $41.46(1.85)$ & \\
\hline No & $2060(98)$ & $36.25(0.27)$ & & $49.05(0.26)$ & \\
\hline
\end{tabular}

${ }^{a}$ Weighted percentages and means, unweighted numbers.

'Effect size=mean for "Yes," minus mean for "No," divided by 10 .

All scores were significantly lower $(P<0.05)$ for patients with the impairment except for the mental component summary for "difficulty walking." 
The latter study also suggested that the effects of fatigue on physical QOL were independent of EDSS disability.

More detailed analysis of the relationship between fatigue and QOL reported significant effects on each domain of the SF-36, ${ }^{51}$ and in a study by Forbes et al., ${ }^{40}$ although quantitative data were not provided for each domain, the authors reported that increasing fatigue severity resulted in incremental decreases in all SF-36 domains except social function and general health. These results suggest a broad impact of fatigue on QOL.

In contrast to the above studies, Wynia et al. ${ }^{42}$ reported that fatigue had a very limited direct impact on QOL, with a significant effect only on the physical functioning domain of the SF-36 $(P<0.05)$, and no effects on any domains of the WHOQOL-BREF. This discrepancy with other studies was ascribed to fatigue mediating its effects through other impairments, which the authors suggested were not adequately adjusted for in other studies. However, given the extent of the presence and severity of fatigue in individuals with MS, it is surprising that direct effects on domains such as vitality were not observed.

Several of the above studies also reported that depression was independently associated with impaired QOL. ${ }^{40,47,48,51}$ While a general finding was that depression is strongly predictive of QOL, ${ }^{50,52}$ it has been specifically reported that the presence of depression resulted in significantly poorer $(P<0.05)$ health perception, role limitations due to emotional dysfunction, health distress, fatigue, sexual function, and emotional well-being. ${ }^{48}$ Data from Forbes et al. ${ }^{40}$ suggested a potential association between severity of depression and specific QOL domains; incremental reductions in scores were observed with increasing depression severity for all SF-36 domains except role physical and general health. Although Wynia et al. ${ }^{42}$ also suggested that depression affects all aspects of QOL, their results were not demonstrative of this, since depression was incorporated into the single variable of general impairment of mental functions, which also included cognitive dysfunction and sleep.

Spasticity has been reported in up to $84 \%$ of patients with MS. Despite the high prevalence of spasticity and its recognized contribution to pain, difficulty in ambulation, poor gait and balance, decreased range of motion, and problems with hygiene, little is known about its specific impact on QOL. ${ }^{53}$ A study using data from the North American Research Committee On Multiple Sclerosis (NARCOMS) patient registry observed a $17 \%$ to $39 \%$ decrease in the physical component score of the SF-36 with each advancing level of spasticity severity relative to individuals with no spasticity, although there appeared to be less of an effect on the mental component score $(12 \%$ reduction even with severe spasticity). ${ }^{53}$ Since there was no adjustment for other factors including disability level, which also appeared to increase with increasing spasticity, it is unclear whether the effects of spasticity on QOL are independent or mediated through other variables. Nevertheless, the study also reported on a more pragmatic outcome of spasticity; spasticity affected daily activities on at least a frequent basis in $44 \%$ of individuals with MS, and prevented daily activities in $4 \%$ of individuals. Similarly, Wu et al. ${ }^{13}$ reported that compared with patients without spasticity, patients who reported spasticity had significantly lower scores $(P<0.05)$ on the physical and mental summary components of the SF-12 (Table 1$).{ }^{13}$

The prevalence of pain in patients with MS, which has been reported as being up to $86 \%,{ }^{54}$ is comparable to that of spasticity. Although pain can be under-recognized as a symptom of importance to MS patients in the clinical setting, several studies have shown that the presence of pain adversely impacts daily function and QOL 
across a wide range of domains. ${ }^{40,55-61}$ Wynia et al. ${ }^{42}$ suggested that pain only impacts the physical domain of QOL, but other studies have consistently reported broader effects; as pain severity increased, significantly lower scores on all SF-36 domains were reported among patients with pain relative to pain-free patients with lower scores (Figure 3). ${ }^{40,56}$ Pain was also found to correlate with mental health aspects of QOL, with significant associations between pain severity and both depression (Spearman $\mathrm{R}=-0.27 ; P<0.001$ ) and anxiety (Spearman $\mathrm{R}=-0.39 ; P<0.001) .{ }^{62}$ Not surprisingly, pain reduced patient independence by limiting participation in activities of daily living ${ }^{55,57}$ and interfered with daily functions including work, sleep, and recreational and social activities, with at least moderate interference on daily life reported by up to nearly half of patients with pain. ${ }^{58-61}$

As previously noted, it has been reported that the presence of other symptoms and impairments in patients with MS result in significantly lower SF-12 scores (Table 1), ${ }^{13}$ but less information is available on the specific contribution of these to the overall burden. Of these impairments, a study by Rao et al. ${ }^{63}$ assessed the contribution of cognitive dysfunction to problems in daily living. They found that relative to cognitively intact patients, those who were cognitively impaired engaged in fewer social and avocational activities, reported more sexual dysfunction, experienced greater difficulty in performing routine household tasks, and exhibited more mood disturbances.

Two studies by Nortvedt et al. ${ }^{64,65}$ are notable not only for their findings that bladder, bowel, and sexual dysfunction result in significantly lower QOL relative to patients without these problems, even after adjusting for EDSS disability, but also for their observations that bladder and sexual dysfunction are present in substantial proportions of patients with low physical disability. Of individuals with EDSS scores $\leq 4,53 \%$ and $44 \%$ had sexual dysfunction and bladder dysfunction, respectively.

\section{ECONOMIC IMPACT OF MS SYMPTOMS AND IMPAIRMENTS}

Lack of appropriate instruments and databases make the contribution of specific symptoms and impairments to costs even more difficult to assess than for QOL. Nevertheless, some relationships can be inferred from available studies. A relationship between walking disability and costs may be imputed by the changes in costs associated with the change in EDSS scores that relate to the various levels of

Figure 3. Mean scores (95\% CI) on the 36-item Short Form (SF-36) quality of life instrument among multiple sclerosis (MS) patients with and without pain. Domains are: physical functioning (PF); role-physical (RP); bodily pain (BP); general health $(\mathrm{GH})$; vitality $(\mathrm{VT})$; social functioning $(\mathrm{SF})$; role-emotional $(\mathrm{SE})$; mental health $(\mathrm{MH}) .{ }^{*} P<0.01$. From Svensden KB et al. Sensory function and quality of life in patients with multiple sclerosis and pain. Pain. 2005;114:473-481. This figure has been reproduced with permission of the International Association for the Study of Pain ${ }^{\circledR}\left(\right.$ IASP $\left.{ }^{\circledR}\right)$. The figure may not be reproduced for any other purpose without permission. ${ }^{56}$

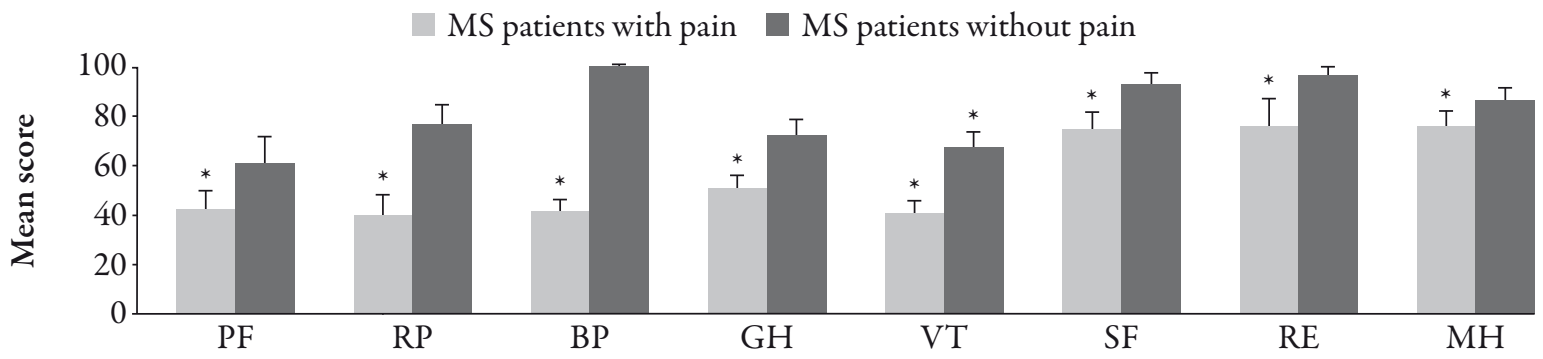


mobility impairment. A review of studies that evaluated costs stratified by EDSS scores showed that moderate walking limitations (EDSS 4.0 to 4.5) increased total costs by up to 3.8 times the cost of patients with low disability (total costs increased from $\$ 7969$ at EDSS 1 to $\$ 30,348$ at EDSS 4), and losing the ability to walk without aid (EDSS 6.5) increased costs up to 7.46-fold (total costs increased from $\$ 932$ at EDSS 1 to $\$ 6952$ at EDSS 6.5). ${ }^{66}$ Among patients with EDSS disability scores 4.0 to 6.0 , characterized by some walking impairment up to the need for constant assistance, nonmedical costs represent a higher proportion of costs than at other disease levels, since more patients are at working age at these disability scores. ${ }^{15,24}$ Additionally, nonmedical costs rise more steeply at earlier disability levels than direct medical costs. ${ }^{66}$ These nonmedical costs are mainly in the form of lost productivity, which has been suggested to be the single highest contributor to the societal burden associated with MS; although at high EDSS scores (EDSS 6.0 to 9.5), which are characterized by severe walking impairment and complete loss of mobility, informal care from family and friends accounted for a large percentage of the patients' total out-of-pocket costs. ${ }^{15,24}$

Productivity is compromised in patients with MS, and impaired mobility in particular has been suggested to be an important factor contributing to lost productivity. In a study by Scheinberg et al., ${ }^{67} 53 \%$ of patients reported physical difficulty as their primary reason for leaving their job. Edgley et al.$^{68}$ more specifically reported that ambulation problems were the primary symptoms in patients who quit working because of MS; $41 \%$ cited impaired mobility, with fatigue the next most frequent symptom (39\%). Using the need for assistive devices as a surrogate for impaired mobility, Kornblith et al. ${ }^{69}$ developed the Mobility Dysfunction Index to evaluate the impact of mobility on employment. Using this index and the statistical technique of path analysis for evaluating causal relationships, the authors concluded that mobility was a major determinant of employment status.

In a recent study by Julian et al. ${ }^{70}$ the NARCOMS patient registry was used to determine patient and disease characteristics that are associated with employment status. Patient data were evaluated cross-sectionally and prospectively over two assessment periods with a mean interval of $1.56 \pm 0.93$ years. This study confirmed the importance of the role of mobility in employment among patients with MS. While worsening of overall symptoms was predictive of unemployment, logistic regression analysis identified two predominant factors as significant predictors for entering and leaving the workforce over time: mobility and hand function. Greater difficulty with mobility and hand function were significantly associated with becoming unemployed, odds ratios of $1.20(P<0.05)$ and 1.25 $(P<0.001)$, respectively. Conversely, reduced difficulty was predictive of re-entering the workforce, odds ratios of 0.82 and 0.83 , respectively $(P<0.05)$. Cognitive dysfunction has also been identified as a factor that impacts productivity in MS, since it has shown to be associated with a lower likelihood of employment. ${ }^{63,70}$ However, none of the studies have provided a quantitative assessment of the lost productivity costs associated with these impairments.

Studies have documented the indirect costs of MS due to lost income, equipment and structural alterations to the home, and formal, paid and informal, unpaid care. In contrast, there are limited quantitative data on component costs that are encompassed by direct medical care. ${ }^{2}$ These component costs are related to the use of both medical (inpatient, outpatient, and emergency) and pharmacy services. Direct medical costs of treatment related to impairments were described for the year 2004 using an administrative claims 
database. ${ }^{2}$ Identification of conditions and costs were based on the presence of International Classification of Disease, 9th Revision, Clinical Modification (ICD-9-CM) codes and Episode Treatment Groups, with the latter used to identify and aggregate claims data for procedures and services relevant to the treatment of MS. When aggregated by clinical condition, patients with medical claims having $\geq 1$ diagnosis code for the presence of specific conditions had a significantly higher average cost of treatment relative to the cost of an average MS episode, which was not specified as disease exacerbation or progression, $(\$ 12,879 \pm \$ 18,583)$ (Table 2$)$, although the standard deviations related to these costs were also very large, since one of the difficulties in characterizing healthcare costs is that they are generally nonparametric. While in this study, optic neuritis was associated with the highest costs, these costs were the most variable, and this impairment also had the lowest frequency. Costs related to abnormality of gait and spasms were approximately $60 \%$ higher than the cost of the average MS episode, and costs related to other conditions ranged from $8 \%$ for depression to $45 \%$ for fecal incontinence, which was also higher than an average MS episode.

Pain also adds to the economic impact of MS, resulting from excess healthcare resource utilization and reduced employment among MS patients with pain relative to those without pain..$^{57,61,71}$ The direct costs associated with MS-associated pain were estimated in a Canadian study; the mean cost was reported to be Canadian $\$ 2528 \pm \$ 5695$, and the median cost was $\$ 753$ (interquartile range $\$ 209$ to $\$ 2061$ ). This apparent disparity in costs is likely due to the fact that resource utilization and its associated costs generally have a nonparametric distribution. Regardless of whether the median

Table 2. Total average annual cost of multiple sclerosis (MS) with selected comorbid conditions presented in order of decreasing costs and compared with the cost of the average MS episode $(\$ 12,879)$. Reprinted with permission from Prescott et al. ${ }^{2}$

\begin{tabular}{lccc}
\hline Condition (ICD-9-CM code) $^{\mathrm{a}}$ & $n$ (\% of total) $^{\mathbf{b}}$ & Average annual cost (SD), \$ $^{\text {P value }}$ \\
\hline Optic neuritis (341.0) & $37(0.4)$ & $39,247(138,557)$ & $<0.001$ \\
Abnormality of gait (781.2) & $744(7.4)$ & $20,871(37,948)$ & $<0.001$ \\
Spasms (781.0) & $333(3.3)$ & $20,376(26,652)$ & $<0.001$ \\
Fecal incontinence (787.6) & $40(0.4)$ & $18,694(14,101)$ & 0.047 \\
Urinary incontinence (788.3) & $558(5.5)$ & $16,898(19,118)$ & $<0.001$ \\
Voice disturbances (784.4, 784.5) & $165(1.6)$ & $16,463(25,537)$ & 0.012 \\
Ataxia (781.3) & $311(3.1)$ & $16,168(19,317)$ & 0.002 \\
Convulsions (780.3) & $349(3.5)$ & $15,664(20,381)$ & 0.004 \\
Malaise and fatigue (780.7) & $2177(21.6)$ & $14,604(17,630)$ & $<0.001$ \\
Depression (ETGs 95 or 96) & $2001(19.8)$ & $13,928(14,757)$ & 0.005 \\
Trigeminal neuralgia (350.1) & $92(0.9)$ & $12,467(17,494)$ & 0.831 \\
Burning, numbness, tingling sensations (782.0) & $1738(17.2)$ & $12,504(14,913)$ & 0.356 \\
Fibromyalgia/myalgia and myositis (729.1) & $744(7.4)$ & $11,478(12,574)$ & 0.033 \\
\hline
\end{tabular}

${ }^{2}$ The prevalence of selected conditions was based on the presence of listed Episode Treatment Groups (ETGs), or one or more International Classification of Diseases, 9th Revision, Clinical Modification (ICD-9-CM) codes present on medical claims any time during the study period.

${ }^{\mathrm{b}}$ Total $n=10,099$.

${ }^{c} P$ values calculated using analysis of variance for comparison with cost of the average MS episode. 
or mean cost is considered, the primary cost driver was the use of pain therapies. ${ }^{71}$ However, it should also be noted that Canada permits a wider range of options that may be used for the treatment of pain including use of cannabinoids; $25 \%$ of patients in the study reported use of marijuana. Interestingly, the presence and severity of pain was not related to EDSS disability scores. Furthermore, the authors also reported that indirect costs resulting from lost work or leisure time due to pain were Canadian $\$ 669 \pm \$ 875$ (median $\$ 264$, interquartile range $\$ 1$ to $\$ 933$ ), and that total costs correlated with levels of self-reported pain. ${ }^{71}$ Direct and indirect costs associated with other symptoms or MS-related disabilities have not been estimated.

As previously mentioned, QOL is substantially affected by MS, and while it may be important to account for the economic impact of QOL in health economic analyses, QOL is considered an intangible cost and is frequently not calculated in burden-of-illness studies due to the difficulty of placing a monetary value on it. Nevertheless, one approach that can be used to estimate the monetary cost for changes in QOL is based on a traditionally accepted value of the willingness to pay for a quality-adjusted life-year (QALY). Using accepted values of US\$60,000 and $€ 50,000$ for a QALY, Kobelt et al. calculated that reduced QOL adds another $\$ 15,315$ to the annual MS-associated costs per individual in the US, ${ }^{15}$ and $€ 13,400$ in the European Union. ${ }^{24}$

A more detailed analysis of the costs associated with reduced QOL, performed in a countryspecific setting (Spain), stratified cost per QALY by EDSS scores (0, 1.0 to 3.0, 3.5 to $5.5,6.0$ to 7.0, 7.5 to 9.5) (Figure 4). ${ }^{72}$ Costs increased as EDSS disability levels increased, with the greatest increase in costs occurring at the EDSS boundary between EDSS intervals of 1.0 to 3.0 and 3.5 to 5.5. It should be noted that scores higher than 3.5 are characterized by a substantial reduction
Figure 4. Intangible costs (Euros; $€$ ) per multiple sclerosis (MS) patient per year according to level of disability on the Expanded Disability Status Scale (EDSS) score based on a value of $€ 55,000$ per quality-adjusted life-year (QALY). Data from Casado et al. ${ }^{72}$

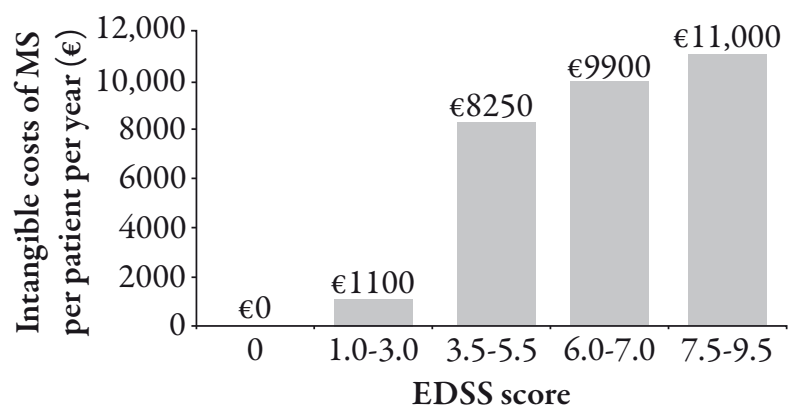

in mobility. These data also suggest that the greatest change in QOL and costs related to QOL occur early in the disease, with only incremental changes at higher levels of EDSS-rated disability. However, the costs associated with symptom-specific reductions in QOL have not been evaluated.

\section{CONCLUSION}

Increasing evidence suggests that the substantial socioeconomic burden associated with MS may arise from impairments and symptoms that may not be adequately reflected by concepts relating to level of disability. Even at low disability levels, patients place a high emphasis on mobility and other symptoms that affect their general and mental health as well as their overall QOL. However, physicians may be more focused on relapse rate reduction and slowing disease progression. Since some of the symptoms may be independent of disease course, further investigation of the contribution of these impairments to the burden of MS is warranted. Additionally, there is not only a need to establish the relationships among the symptoms and their contributions to the overall reduction with regard to the effects of these impairments on employment 
and productivity; importantly, there is also a need for consistent vigilance for the effects of these disabilities, and optimizing treatment regimens that target specific impairments. Effective intervention can ultimately decrease healthcare costs while improving patient QOL.

\section{ACKNOWLEDGMENTS}

\section{Sponsored by Acorda Therapeutics,} Hawthorne, NY. In accordance with best practices, the author retained complete control over content. Acorda was provided with a courtesy review of the manuscript prior to journal submission. The author has received grants for clinical research and educational activities from Teva Neuroscience and has served as an advisor or consultant to Acorda Therapeutics, Bayer HealthCare Pharmaceuticals, Biogen, Genentech, Serono, and Teva Neuroscience. Editorial assistance in the preparation of this manuscript was provided by E. Jay Bienen, PhD, and was funded by Acorda Therapeutics.

\section{REFERENCES}

1. National Multiple Sclerosis Society web site. About MS. Available at: http://www.nationalmssociety. org/about-multiple-sclerosis/index.aspx. Accessed April 3, 2009.

2. Prescott JD, Factor S, Pill M, Levi GW. Descriptive analysis of the direct medical costs of multiple sclerosis in 2004 using administrative claims in a large nationwide database. J Manag Care Pharm. 2007;13:44-52.

3. Minden S, Hoaglin D, Jureidini S, et al. Diseasemodifying agents in the Sonya Slifka Longitudinal Multiple Sclerosis Study. Mult Scler. 2008;14: 640-655.

4. Richards RG, Sampson FC, Beard SM, Tappenden P. A review of the natural history and epidemiology of multiple sclerosis: implications for resource allocation and health economic models. Health Technol Assess. 2002;6:1-73.
5. Schwendimann RN. Treatment of symptoms in multiple sclerosis. Neurol Res. 2006;28:306-315.

6. Henze T, Rieckmann P, Toyka KV; Multiple Sclerosis Therapy Consensus Group (MSTCG) of the German Multiple Sclerosis Society. Symptomatic treatment of multiple sclerosis. Multiple Sclerosis Therapy Consensus Group (MSTCG) of the German Multiple Sclerosis Society. Eur Neurol. 2006;56:78-105.

7. Boissy AR, Cohen JA. Multiple sclerosis symptom management. Expert Rev Neurother. 2007;7: 1213-1222.

8. Cohen BA. Identification, causation, alleviation, and prevention of complications (ICAP): an approach to symptom and disability management in multiple sclerosis. Neurology. 2008;71 (suppl. 3):S14-S20.

9. Rothwell PM, McDowell Z, Wong CK, Dorman PJ. Doctors and patients don't agree: cross sectional study of patients' and doctors' perceptions and assessments of disability in multiple sclerosis. BMJ. 1997;314:1580-1583.

10. Hemmett L, Holmes J, Barnes M, Russell N. What drives quality of life in multiple sclerosis? QJM. 2004;97:671-676.

11. Nortvedt MW, Riise T, Myhr KM, Nyland HI. Quality of life in multiple sclerosis: measuring the disease effects more broadly. Neurology. 1999;53: 1098-1103.

12. Solari A, Radice D. Health status of people with multiple sclerosis: a community mail survey. Neurol Sci. 2001;22:307-315.

13. Wu N, Minden SL, Hoaglin DC, Hadden L, Frankel D. Quality of life in people with multiple sclerosis: data from the Sonya Slifka Longitudinal Multiple Sclerosis Study. J Health Hum Serv Adm. 2007;30:233-267.

14. Gottberg K, Einarsson U, Ytterberg C, et al. Healthrelated quality of life in a population-based sample of people with multiple sclerosis in Stockholm County. Mult Scler. 2006;12:605-612.

15. Kobelt G, Berg J, Atherly D, Hadjimichael O. Costs and quality of life in multiple sclerosis: a crosssectional study in the United States. Neurology. 2006;66:1696-1702.

16. Orme M, Kerrigan J, Tyas D, Russell N, Nixon R. The effect of disease, functional status, and relapses on the utility of people with multiple sclerosis in the UK. Value Health. 2007;10:54-60. 
17. Jones CA, Pohar SL, Warren S, Turpin KVL, Warren KG. The burden of multiple sclerosis: a community health survey. Health Qual Life Outcomes. 2008;6:1.

18. Kurtzke JF. Rating neurologic impairment in multiple sclerosis: an expanded disability status scale (EDSS). Neurology. 1983;33:1444-1452.

19. Martin CL, Phillips BA, Kilpatrick TJ, et al. Gait and balance impairment in early multiple sclerosis in the absence of clinical disability. Mult Scler. 2006;12:620-628.

20. Goldman M, Marrie RA, Cohen JA. Evaluation of the six-minute walk in multiple sclerosis subjects and healthy controls. Mult Scler. 2008;14:383-390.

21. Johansson S, Ytterberg C, Claesson IM, et al. High concurrent presence of disability in multiple sclerosis. Associations with perceived health. J Neurol. 2007;254:767-773.

22. Kurtzke JF, Wallin MT. Epidemiology. In: Burks JS, Johnson KP, eds. Multiple Sclerosis: Diagnosis, Medical Management, and Rehabilitation. New York: Demos Medical Publishing, Inc; 2000:49-71.

23. Whetten-Goldstein K, Sloan FA, Goldstein LB, Kulas ED. A comprehensive assessment of the cost of multiple sclerosis in the United States. Mult Scler. 1998;4:419-425.

24. Kobelt G, Berg J, Lindgren P, Fredrikson S, Jönsson B. Costs and quality of life of patients with multiple sclerosis in Europe. J Neurol Neurosurg Psychiatry. 2006;77:918-926.

25. Kobelt G, Berg J, Lindgren P, Kerrigan J, Russell N, Nixon R. Costs and quality of life of multiple sclerosis in the United Kingdom. Eur J Health Econ. 2006;7(suppl. 2):S96-S104.

26. McCrone $\mathrm{P}$, Heslin $\mathrm{M}$, Knapp $\mathrm{M}$, Bull $\mathrm{P}$, Thompson A. Multiple sclerosis in the UK: service use, costs, quality of life and disability. Pharmacoeconomics. 2008;26:847-860.

27. Ware JE Jr, Sherbourne CD. The MOS 36-item short-form health survey (SF-36). I. Conceptual framework and item selection. Med Care. 1992;30: 473-483.

28. Ware JE, Kosinski M, Keller SD. A 12-item short form health survey (SF-12): construction of scales and preliminary tests of reliability and validity. Med Care. 1996;32:220-233.
29. Vickrey BG, Hays RD, Harooni R, Myers LW, Ellison GW. A health-related quality of life measure for multiple sclerosis. Qual Life Res. 1995;4: 187-206.

30. Feeny D, Furlong W, Boyle M, Torrance GW. Multiattribute health status classification systems. Health Utilities Index. Pharmacoeconomics. 1995;7:490502.

31. The EuroQuol Group. EuroQol-a new facility for the measurement of health-related quality of life. The EuroQol Group. Health Policy. 1990;16: 199-208.

32. The WHOQOL Group. Development of the World Health Organization WHOQOL-BREF quality of life assessment. Psychol Med. 1998;28:551-558.

33. Hobart J, Lamping D, Fitzpatrick R, Riazi A, Thompson A. The Multiple Sclerosis Impact Scale (MSIS-29): a new patient-based outcome measure. Brain. 2001;124:962-973.

34. Swingler RJ, Compston DA. The morbidity of multiple sclerosis. Q J Med. 1992;83:325-337.

35. World Health Organization (WHO). International Classification of Functioning, Disability and Health (ICF). Available at: http://www.who.int/classifications/icfbrowser/. Accessed April 3, 2009.

36. Myhr KM, Riise T, Vedeler C, et al. Disability and prognosis in multiple sclerosis: demographic and clinical variables important for the ability to walk and awarding of disability pension. Mult Scler. 2001;7:59-65.

37. Paltamaa J, Sarasoja T, Leskinen E, Wikström J, Mälkiä E. Measures of physical functioning predict self-reported performance in self-care, mobility, and domestic life in ambulatory persons with multiple sclerosis. Arch Phys Med Rehabil. 2007;88:16491657.

38. Datamonitor Healthcare Reports. Treatment algorithms 1999: segmenting the multiple sclerosis patient population. London, UK: Datamonitor Healthcare Reports; 1999.

39. Heesen C, Bohm J, Reich C, Kasper J, Goebel M, Gold SM. Patient perception of bodily functions in multiple sclerosis: gait and visual function are the most valuable. Mult Scler. 2008;14:988-991.

40. Forbes A, While A, Mathes L, Griffiths P. Health problems and health-related quality of life in people with multiple sclerosis. Clin Rehabil. 2006;20:67-78. 
41. Fisk JD, Pontefract A, Ritvo PG, Archibald CJ, Murray TJ. The impact of fatigue on patients with multiple sclerosis. Can J Neurol Sci. 1994;21:9-14.

42. Wynia K, Middel B, van Dijk JP, De Keyser JH, Reijneveld SA. The impact of disabilities on quality of life in people with multiple sclerosis. Mult Scler. 2008;14:972-980.

43. Hadjimichael O, Vollmer T, Oleen-Burkey M; North American Research Committee on Multiple Sclerosis. Fatigue characteristics in multiple sclerosis: the North American Research Committee on Multiple Sclerosis (NARCOMS) survey. Health Qual Life Outcomes. 2008;6:100.

44. Kos D, Kerckhofs E, Nagels G, D'hooghe MB, Ilsbroukx S. Origin of fatigue in multiple sclerosis: review of the literature. Neurorehabil Neural Repair. 2008;22:91-100.

45. The Canadian Burden of Illness Study Group. Burden of illness of multiple sclerosis: Part II: Quality of life. Can J Neurol Sci. 1998;25:31-38.

46. Pfennings L, Cohen L, Miller D, et al. Using the Short Form-36 with multiple sclerosis patients in five countries: a cross-cultural comparison. Psychol Rep. 1999;85:19-31.

47. Amato MP, Ponziani G, Rossi F, Liedl CL, Stefanile C, Rossi L. Quality of life in multiple sclerosis: the impact of depression, fatigue and disability. Mult Scler. 2001;7:340-344.

48. Janardhan V, Bakshi R. Quality of life in patients with multiple sclerosis: the impact of fatigue and depression. J Neurol Sci. 2002;205:51-58.

49. Merkelbach S, Sittinger H, Koenig J. Is there a differential impact of fatigue and physical disability on quality of life in multiple sclerosis? J Nerv Ment Dis. 2002;190:388-393.

50. Benedict RH, Wahlig E, Bakshi R, et al. Predicting quality of life in multiple sclerosis: accounting for physical disability, fatigue, cognition, mood disorder, personality, and behavior change. J Neurol Sci. 2005;231:29-34.

51. Pittion-Vouyovitch S, Debouverie M, Guillemin F, Vandenberghe N, Anxionnat R, Vespignani $\mathrm{H}$. Fatigue in multiple sclerosis is related to disability, depression and quality of life. J Neurol Sci. 2006;243:39-45.

52. Fruehwald S, Loeffler-Stastka H, Eher R, Saletu B, Baumhackl U. Depression and quality of life in multiple sclerosis. Acta Neurol Scand. 2001;104: 257-261.
53. Rizzo MA, Hadjimichael OC, Preiningerova J, Vollmer TL. Prevalence and treatment of spasticity reported by multiple sclerosis patients. Mult Scler. 2004;10:589-595.

54. O'Connor AB, Schwid SR, Herrmann DN, Markman JD, Dworkin RH. Pain associated with multiple sclerosis: systematic review and proposed classification. Pain. 2008;137:96-111.

55. Grasso MG, Clemenzi A, Tonini A, et al. Pain in multiple sclerosis: a clinical and instrumental approach. Mult Scler. 2008;14:506-513.

56. Svendsen KB, Jensen TS, Hansen HJ, Bach FW. Sensory function and quality of life in patients with multiple sclerosis and pain. Pain. 2005;114:473481 .

57. Khan F, Pallant J. Chronic pain in multiple sclerosis: prevalence, characteristics, and impact on quality of life in an Australian community cohort. J Pain. 2007;8:614-623.

58. Hadjimichael O, Kerns RD, Rizzo MA, Cutter G, Vollmer T. Persistent pain and uncomfortable sensations in persons with multiple sclerosis. Pain. 2007; 127:35-41.

59. Beiske AG, Pedersen ED, Czujko B, Myhr KM. Pain and sensory complaints in multiple sclerosis. Eur J Neurol. 2004;11:479-482.

60. Svendsen KB, Jensen TS, Overvad K, Hansen HJ, Koch-Henriksen N, Bach FW. Pain in patients with multiple sclerosis: a population-based study. Arch Neurol. 2003;60:1089-1094.

61. Ehde DM, Gibbons LE, Chwastiak L, Bombardier CH, Sullivan MD, Kraft GH. Chronic pain in a large community sample of persons with multiple sclerosis. Mult Scler. 2003;9:605-611.

62. Kalia LV, O'Connor PW. Severity of chronic pain and its relationship to quality of life in multiple sclerosis. Mult Scler. 2005;11:322-327.

63. Rao SM, Leo GJ, Ellington L, Nauertz T, Bernardin L, Unverzagt F. Cognitive dysfunction in multiple sclerosis. II. Impact on employment and social functioning. Neurology. 1991;41:692-696.

64. Nortvedt MW, Riise T, Myhr KM, Landtblom AM, Bakke A, Nyland HI. Reduced quality of life among multiple sclerosis patients with sexual disturbance and bladder dysfunction. Mult Scler. 2001;7: 231-235. 
65. Nortvedt MW, Riise T, Frugård J, et al. Prevalence of bladder, bowel and sexual problems among multiple sclerosis patients two to five years after diagnosis. Mult Scler. 2007;13:106-112.

66. Patwardhan MB, Matchar DB, Samsa GP, McCrory DC, Williams RG, Li TT. Cost of multiple sclerosis by level of disability: a review of literature. Mult Scler. 2005;11:232-239.

67. Scheinberg L, Holland N, Larocca NG, Laitin P, Bennett A, Hall H. Multiple sclerosis. Earning a living. N Y State J Med. 1980;80:1395-1400.

68. Edgley K, Sullivan M, Dehoux E. A survey of multiple sclerosis: II. Determinants of employment status. Can J Rehabil. 1991;4:127-132.
69. Kornblith AB, LaRocca NG, Baum HM. Employment in individuals with multiple sclerosis. Int J Rehabil Res. 1986;9:155-165.

70. Julian LJ, Vella L, Vollmer T, Hadjimichael O, Mohr DC. Employment in multiple sclerosis: exiting and re-entering the work force. J Neurol. 2008;255:1354-1360.

71. Piwko C, Desjardins OB, Bereza BG, et al. Pain due to multiple sclerosis: analysis of the prevalence and economic burden in Canada. Pain Res Manag. 2007;12:259-265.

72. Casado V, Romero L, Gubieras L, et al. An approach to estimating the intangible costs of multiple sclerosis according to disability in Catalonia, Spain. Mult Scler. 2007;13:800-804. 